\title{
AC 2011-25: IMPACTS OF THE VANDERBILT UNIVERSITY RESEARCH EXPERIENCE FOR TEACHERS PROGRAM 2008-2010: ANALYSIS OF STUDENT SURVEYS REGARDING MOTIVATIONAL IMPACT
}

\section{Stacy S Klein-Gardner, Vanderbilt University}

Stacy Klein-Gardner is the Director of STEM Outreach for Peabody College and the School of Engineering at Vanderbilt University. She is an associate professor of the practice of Biomedical Engineering, Teaching \& Learning, and Radiological Sciences.

\section{Amber C. Spolarich, North Carolina State University}

Amber Spolarich is currently a senior at North Carolina State University majoring in chemical engineering with a concentration in green chemistry. She has worked with outreach programs through the university that have placed her in local public schools to act as a resource for science, math, and engineering related courses in the hopes of elevating excitement for learning in K-12 classrooms. She has also conducted research in conjunction with the Vanderbilt Instruction in Biomedical Engineering for Secondary science (VIBES) program which aids high school teachers in bringing engineering education into their classrooms. 


\title{
Impacts of the Vanderbilt University Research Experience for Teachers Program 2008-2010: Analysis of Student Surveys Regarding Motivational Impact
}

\begin{abstract}
The Vanderbilt University Bioengineering Research Experience for Teachers (RET) Program allows teachers to complete twenty-three (23) days of research and develop a curriculum unit that incorporates their research in a way that is appropriate for their individual classrooms. It was the hypothesis that the research-based curriculum units developed by the RET participants would engage students in the learning process and result in a higher level of interest in science and engineering during the unit; in turn, leading to increased levels of student motivation as compared to a control teacher's instruction. To determine student motivation, a survey instrument was developed, consisting of twenty (20) questions and based on the following four points of interest: (1) the student's view of the classroom experience, (2) the student's ability to relate the lesson to life, (3) the student's immediate level of interest in the class, and (4) the student's enjoyment of the topic. The research was conducted in the high school/middle school classrooms of teachers who participated in the RET program. High school and middle school students, aged 12-18, were recruited from several area schools. It was found that the students' ability to relate the lesson to life and the student's enjoyment of the topic were significantly greater than the control classroom. While long-term effects were not taken into account, these results did provide evidence that the RET program and its associated researchbased modules positively affected student motivation.
\end{abstract}

\section{Introduction}

Sponsored by the National Science Foundation (NSF), the goal of the Research Experience for Teachers program has been to support "the active involvement of K-12 teachers and community college faculty in engineering research in order to bring knowledge of engineering and technological innovation into their classrooms." In the winter of 2003, Vanderbilt University was awarded a site award for this program to host the "Vanderbilt Biomedical Engineering RET Site Project.” Held in the summers of 2004, 2005, and 2006, this program was designed with the previously discussed professional development characteristics in mind. Supplemental funding allowed for the continuation of the program into the summer of 2007, and a new NSF award was received in 2008 to fund the 2008-2010 summers. The specific goals of the RET Site Project were to instruct teachers about the educational research taking place at Vanderbilt through the NSF funded Vanderbilt Northwestern Texas Harvard-MIT Engineering Research Center (VaNTH ERC) and to give teachers a broad overview of biomedical engineering by engaging them in meaningful research experiences and assisting them in the application of this research in their high school science and mathematics classrooms. Upon 
completion of the program, it was the expectation that lasting partnerships would be created between their respective schools and Vanderbilt University. ${ }^{1,2,3}$

In order to implement their research into a curriculum, RET participants created modules that followed the Legacy Cycle, a form of inquiry-based learning. It has been established that students are more likely to accept new knowledge if they know that it is useful and others can benefit from it. ${ }^{4}$ In the Challenge Question of the Legacy Cycle, students are presented with an open-ended scenario that relates an everyday experience to math, science, and engineering concepts. ${ }^{5}$ Through this classroom set-up, students are more apt to learn if they believe they have played a part in determining how and what they will be learning. ${ }^{6}$ The Legacy Cycle encourages this type of learning environment directly from the beginning. For preparatory work regarding a new topic, many students are asked to brainstorm during the Generate Ideas phase in order to compile their current knowledge and produce hypotheses about the Challenge Question. Upon discussing them, students proceed to determine the concepts they deem necessary to focus on in order to find a solution. ${ }^{7}$ The Multiple Perspectives phase asks for students to analyze information from teacher-selected outside sources in the hopes of pointing them in the right direction. These sources can include web sites, clips from scientific videos, or even interviews from experts in the field of study. Later, in the Research \& Revise stage, students are asked to revise their original ideas based on new information they have found via readings, lectures, or websites. They develop the skills necessary to find the needed information then analyze, discuss, and present their revised ideas. ${ }^{8}$ At this point, the Test Your Mettle phase provides a formative assessment, reinforcing the previous instruction and allowing the teacher to modify and adapt to fit the learners' needs, providing remediation as needed. Finally, the Go Public phase presents students with a hands-on version of a summative assessment, allowing them to work together in groups to plan, design, implement, and report a final project that answers the challenge question.

Upon completing twenty-three days of research, the RET teachers spent three days developing a module that, while still based on teaching standards, incorporates their research at Vanderbilt University in a way that is appropriate for their individual classrooms. One such Legacy Cycle curriculum created by an RET teacher provided students the opportunity to learn about ecological relationships by educating them on topics such as the exchange of energy and matter within food webs, species adaptations, biomimicry, and sustainable design in order to find a solution to the Challenge

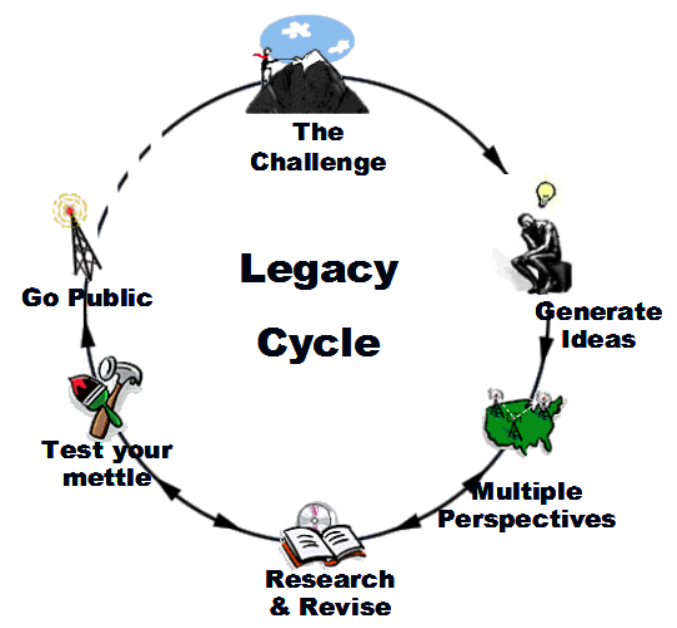

Figure 1: STAR Legacy Cycle Diagram. Question: designing a sustainable guest village in a desert-based national park. ${ }^{9}$ To begin the Legacy Cycle, students first Generated Ideas by 
brainstorming and sharing their responses to journal entries regarding necessary background knowledge. They were then exposed to Multiple Perspectives as they watched several video clips of experts in ecology and biomimetics. After numerous lectures and labs, students Researched \& Revised their previous solutions to the Challenge Question. Later, students used a computer simulation model to predict and manipulate the population densities of desert species and observe the outcomes to Test Their Mettle. To conclude the cycle with the Go Public phase, student teams designed a conceptual, sustainable eco-tourist village which was presented to the class with diagrams, sketches, and an explanation of its suitability to the desert environment.

We evaluated the effectiveness of the curricula developed through the RET program based on the following research question: Does the use of this challenge-based instruction increase the motivational impact of teaching units? We developed the hypothesis that students would find science and engineering more exciting, interesting, and applicable to their daily lives because of their teacher's participation in the RET program. This would be reflected in higher student motivational levels during the instruction of the RET teacher's research-based module as compared to a control teacher's instruction.

\section{Student Motivation Survey}

In order to gauge student motivation, an anonymous survey instrument was developed. This survey was based on a previous survey designed by Peter Häussler and Lore Hoffmann utilized to measure the impact of new physics curriculums and teaching methods and edited to measure interest in engineering rather than physics. ${ }^{10}$

The survey consisted of twenty (20) questions completed on a Likert rating scale in which the student respondents gauged their level of agreement to each individual statement. ${ }^{11}$

The scale utilized is as follows:

1- Completely Disagree

2- Disagree

3- Undecided

4- Agree

5- Completely Agree

The twenty (20) questions were divided into groups of five and focused on four major points of interest regarding motivation: (1) the student's awareness and interest in the topic outside of class, (2) the student's ability to relate the lesson to life, (3) the student's immediate level of interest in the class, and (4) the student's enjoyment of the topic. 


\begin{tabular}{|c|c|c|}
\hline \multirow{5}{*}{1} & 1. I think about the class information outside of class. & 12345 \\
\hline & 2. I discuss what we have learned lately in this class with my classmates. & 12345 \\
\hline & 3. I discuss what we have learned lately in this class outside of school. & 12345 \\
\hline & 4. I have not reflected on the impact of what we have learned lately in this class. & 12345 \\
\hline & 5. It would catch my attention if someone else brought up in conversation & 12345 \\
\hline \multirow{5}{*}{2} & 6. These lessons deal with things which I also encounter in everyday life. & 12345 \\
\hline & 7. I have seen what we have learned lately in the world around me. & 12345 \\
\hline & 8. I can apply what we have learned lately to my everyday life. & 12345 \\
\hline & 9. I am never going to need to know this information outside of class. & 12345 \\
\hline & 10. I have used what we have learned lately to solve a problem outside of class. & 12345 \\
\hline \multirow{5}{*}{3} & 11. I look forward to going to this class. & 12345 \\
\hline & 12. School would be more fun if more classes were like this one. & 12345 \\
\hline & 13. I find the recent information dull and/or uninteresting. & 12345 \\
\hline & 14. I enjoy being in this class. & 12345 \\
\hline & 15. The teacher does not inspire me to learn. & 12345 \\
\hline \multirow{5}{*}{4} & 16. I would like to learn more about the topics we have covered lately. & 12345 \\
\hline & 17. I am interested in taking further classes on these recent topics. & 12345 \\
\hline & $\begin{array}{l}\text { 18. I am interested in reading more books and/or articles } \\
\text { about the topics we have covered lately. }\end{array}$ & 12345 \\
\hline & 19. The topic we have covered recently in this class does not inspire me to learn. & 12345 \\
\hline & $\begin{array}{l}\text { 20. I would not watch a few minutes of a TV show on the topic we have } \\
\text { learned lately in this class. }\end{array}$ & 12345 \\
\hline
\end{tabular}

Validity of the student motivation survey was established upon its successful review by three experts: a teaching and learning faculty member, a high school science teacher, and a science education doctoral student who was a former high school science teacher. Minor revisions suggested by the reviewers were incorporated into the survey before its use. To measure reliability, Cronbach's alpha was utilized. Commonly used as a measure of internal consistency of psychometric test scores, Cronbach's alpha produces a number between 0 and 1 (with 1 being optimal). Obtaining a value of 0.70 or greater is considered favorable. ${ }^{12}$ The reliability data is provided in Table 1.

Table 1: Reliability Justification Based on the Utilization of Cronbach's Alpha. The reliability of the student motivation survey was justified based on the high value of Cronbach's alpha (greater than 0.70) in all four categories.

\begin{tabular}{|c|c|c|c|}
\hline Student Motivation Category & Survey Questions Involved & Student Motivation Description & Cronbach's Alpha \\
\hline 1 & $1-5$ & $\begin{array}{c}\text { The student's awareness and } \\
\text { interest in the topic outside of } \\
\text { class. }\end{array}$ & 0.723 \\
\hline 2 & $6-10$ & $\begin{array}{c}\text { The student's ability to relate } \\
\text { the lesson to life. }\end{array}$ & 0.753 \\
\hline 3 & $11-15$ & $\begin{array}{c}\text { The student's immediate level } \\
\text { of interest in the class. }\end{array}$ & 0.846 \\
\hline
\end{tabular}




\begin{tabular}{|c|c|c|c|}
\hline 4 & $16-20$ & $\begin{array}{c}\text { The student's enjoyment of the } \\
\text { topic. }\end{array}$ & 0.826 \\
\hline
\end{tabular}

\section{Participants}

After the study was approved by the Vanderbilt University Institutional Review Board, a letter was sent to the principals of the teachers who participated in the RET program in the summers of 2008 and 2009 asking the principals for permission to allow the study at their school. The principals were asked to mail a letter of consent. If the principal stated that district approval was also necessary, a letter was mailed to the head of the school district requesting consent. If consent was granted by a school, a letter (and an identical electronic copy) was then sent to the RET teacher(s) at that school, asking if he/she would be interested in presenting the surveys to his/her students. If a teacher consented, the surveys and a procedure of how to distribute them would be provided. The procedure required the teachers to inform the students that their participation was voluntary and their responses were completely anonymous. Both student assent and parental consent were obtained prior to having a student participate in the study. In order to find control teachers at the same school, the consenting principal was asked to email or mail a list of teachers who taught the same or similar subjects at their school. Those teachers were mailed a letter (in addition to an identical electronic copy) asking if they would be willing to serve as control teachers. The control teachers would give the same three surveys to their classes. The same student letter would also be distributed to the control teachers' students and the same procedures would be used.

The participating middle and high school RET teachers included six (6) science teachers, three (3) mathematics teachers, and one (1) technology teacher. Not every experimental teacher was able to find a control teacher at his or her school, so data were taken from four control teachers: two (2) science teachers and two (2) mathematics teachers. Information about the participating RET teachers and their corresponding control teachers can be found in Table 2. Demographic data for these participating schools can be found in Table 3.

High school and middle school students, aged 12-18, were recruited from the participating schools where their principal and teacher had given informed consent. By focusing on middle school and high school students, it is the hope that the students will pursue an advanced math and science track and continue to follow their interest in STEM-related curriculum upon attending a university. It has been reported by the American College Testing Organization that the number of students interesting in pursuing an interest in engineering dropped from 9\% to 6\% between the years 1992 and $2003 .{ }^{13}$ The participating students came from school in suburban, urban, and rural areas. In addition, the participating schools were both private and public. By doing so, it was the hope of the RET program to reach all students and not focus on simply one demographic: the lack of students in engineering does not only apply to minority students. Of the total 368 student participants, 299 were experimental and the remaining 68 were control. 
Table 2: Participating Teacher Demographics. Data regarding the level of experience between the RET and control teachers was collected. Each line of the table represents a different school. Only four RET teachers were able to find a consenting control teacher to participate.

\begin{tabular}{|c|c|c|}
\hline \multicolumn{2}{|c|}{$\begin{array}{c}\text { Years of Teaching } \\
\text { Experience }\end{array}$} & $\begin{array}{c}\text { Subject } \\
\text { Taught }\end{array}$ \\
\hline$R E T$ & Control & \\
\hline 7 & & Science \\
\hline 8 & 5 & Science \\
\hline 1 & 5 & Math \\
\hline 7 & & Science \\
\hline 16 & & Science \\
\hline 17 & & Technology \\
\hline 3 & & Math \\
\hline 10 & 2 & Science \\
\hline 23 & 10 & Math \\
\hline 7 & & Science \\
\hline
\end{tabular}

Table 3: School Demographic Data. Demographic data was collected from all participating schools including the type of school in addition to student race, gender, and population.

\begin{tabular}{|c|l|c|c|c|c|c|c|c|c|}
\hline School & \multicolumn{1}{|c|}{ Type } & \multicolumn{5}{|c|}{ Demographic (\%) } & \multicolumn{2}{c|}{ Gender (\%) } & Population \\
\hline & & White & Black & Hispanic & $\begin{array}{l}\text { American } \\
\text { Indian }\end{array}$ & Asian & Male & Female & \\
\hline 1 & rural, public & 93 & 4 & 2 & 1 & 1 & 50 & 50 & 1080 \\
\hline 2 & $\begin{array}{l}\text { suburban, } \\
\text { private }\end{array}$ & 93 & 4 & $<1$ & $<1$ & 2 & 100 & 0 & 657 \\
\hline 3 & $\begin{array}{l}\text { suburban/urban, } \\
\text { private }\end{array}$ & 79 & 12 & $<1$ & $<1$ & 9 & 50 & 50 & 916 \\
\hline 4 & rural, public & 70 & 23 & 5 & 1 & 1 & 51 & 49 & 1397 \\
\hline 5 & $\begin{array}{l}\text { puburban, } \\
\text { private }\end{array}$ & 94 & 2 & $<1$ & $<1$ & 4 & 0 & 100 & 553 \\
\hline 6 & rural, public & 87 & 8 & 4 & 1 & 1 & 51 & 49 & 551 \\
\hline 7 & rural, public & 14 & 85 & 1 & $<1$ & 1 & 53 & 47 & 1088 \\
\hline 8 & rural, public & 95 & 4 & 1 & $<1$ & 1 & 53 & 47 & 741 \\
\hline 9 & rural, public & 95 & 2 & 2 & 1 & 1 & 54 & 46 & 701 \\
\hline
\end{tabular}

\section{Methods}

RET teachers gave the survey regarding motivational impact to their students prior to and after the completion of their specific RET designed module. The control teachers gave the surveys to their students before and after a different curriculum unit agreed upon by both the RET and control teachers. The time between pre- and post-surveys was approximately the same for both control and RET teachers. 
The pre- and post-surveys were matched and entered into a spreadsheet. Each of the four categories regarding student motivation (1-4 above) had five questions. The scores (1-5, based on the Likert scale) from each set of five questions were added together to give a final sum (5-25 possible) for each category of interest. In order to maintain consistency throughout the survey, the scores of negatively phrased questions were reversed with " 5 " reflecting most positively upon the curricular unit. Differences were then calculated by subtracting each of the sums of the four motivational categories of the pre-survey from the respective sums of the post-survey. In comparing the differences, a non-paired t-test (assuming unequal variances) was run on each of the four category's data to determine if student motivation increased as a result of teacher participation in the RET program and his or her implementation of the teaching unit. It was found that categories 2 and 4 (the student's ability to relate the lesson to life and the student's enjoyment of the topic, respectively) were significantly different at the $\mathrm{p}<0.05$ and $\mathrm{p}<0.01$ levels, respectively. This data can be found in Figure 2.

Figure 2: Comparison of Motivations 1-4: Control vs. Experimental. A non-paired t-test showed that categories 2 and 4 were significantly different at the $\mathrm{p}<0.05$ and $\mathrm{p}<0.01$ levels.

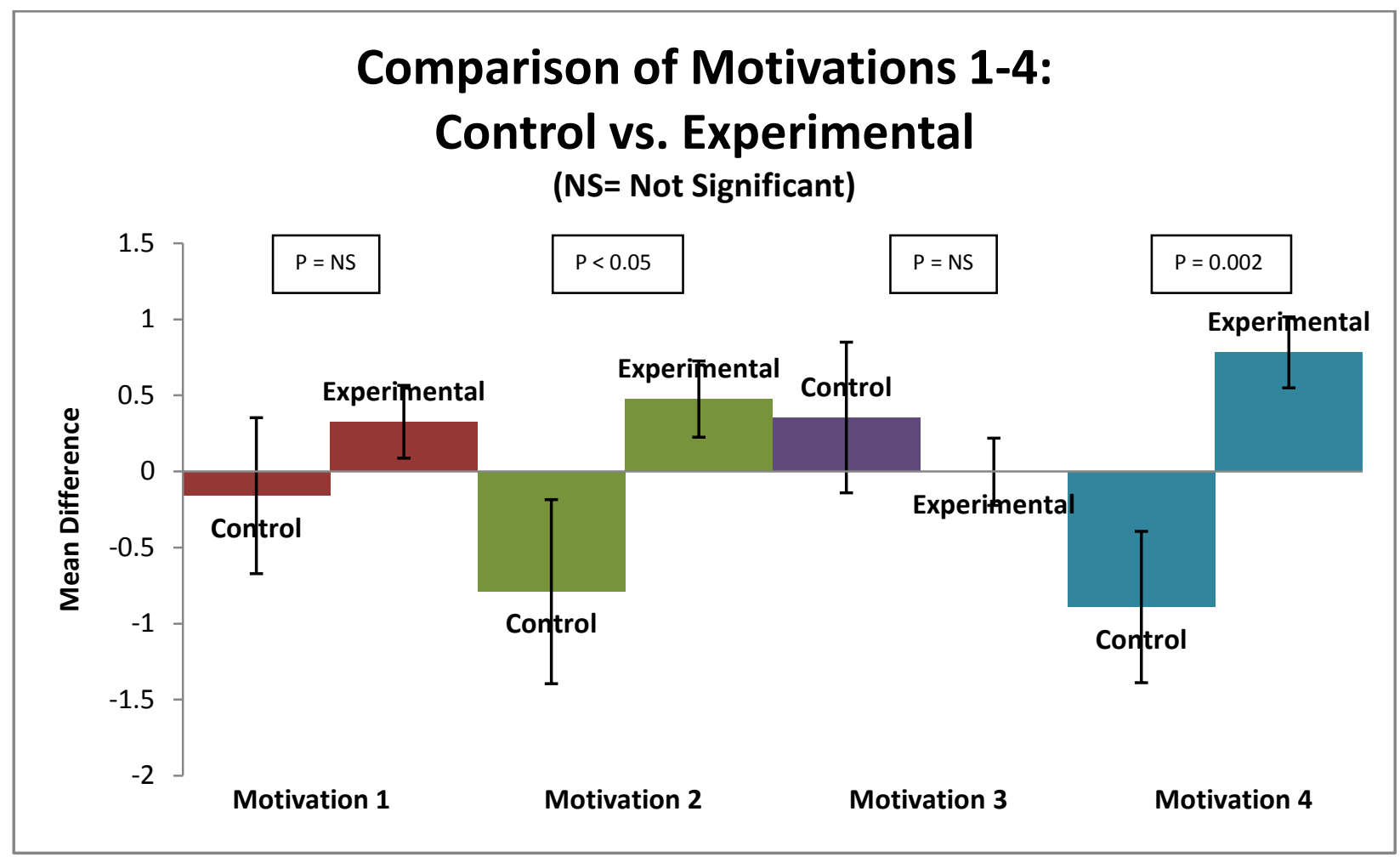

\section{Analysis}

Upon analyzing the data, we found that the experimental (RET) teachers' students showed a strong positive difference between pre- and post-surveys in motivational categories 2 (the student's ability to relate the lesson to life) and 4 (the student's enjoyment of the topic). Conversely, the control teachers showed a negative difference between pre- and post-surveys, 
although we originally assumed their scores would remain unchanged. By implementing their research-based curriculum, the RET teachers were able to directly engage the students through participation in many activities that incorporated writing, designing, creating, and solving; in

turn, leading them to master the material. ${ }^{14}$ Basing the classroom activities on everyday problems and topics that are relevant to the students' lives provided a way for them to readily accept the new knowledge. ${ }^{15}$ In correlation with previous studies, this problem-based learning has demonstrated the enhancement of student motivation and interest in the subject matter by emphasizing "meaning-making over fact-collecting." ${ }^{, 16}$ It also confirmed that problem-based learning has a positive impact on the entire learning process. Through research-based modules, the RET program forms a foundation for generating immediate student interest and sustaining motivation. ${ }^{17}$

Motivational categories 1 (the student's view of the classroom experience) and 3 (the student's level of interest in the class) provided data that were not statistically significant. Many times, this is the students' first exposure to the format of the Legacy Cycle. This format pushes them to think in different ways than they commonly have done before. By diving much deeper into a topic, students are required to utilize a great deal of reasoning rather than simple memorization. They are learning actual scientific processes in addition to new thought processes they have not experienced and they mistake it for extra work and do not appreciate it for what it truly is worth. There is also the possibility that, while students enjoyed the curricular unit and topic, they were essentially unwilling to change their view of the classroom experience.

\section{Comparison to Other RET Programs}

Fulfilling the NSF goal of the RET program, the Vanderbilt RET program has allowed teachers to utilize their research experiences and successfully translate them into real-world contexts when developing curricula and exposing students to the engineering process. This study reports unique student-level results in which students self-report an increase in enjoyment and ability to relate the curriculum unit to real-life. A few RET programs have found success comparable to that of Vanderbilt University in program implementation, though student level results have not been reported. The Georgia Institute of Technology's Physics RET program saw similar results: a majority of the teachers claimed the program gave them the ability to encourage students effectively to pursue a major in science or engineering. ${ }^{18}$ In addition, the Polytechnic Institute of New York University also found that their RET program allowed their participants to conduct inquiry-based teaching successfully while engaging the students in STEM-related curricula. ${ }^{19}$ The Texas A\&M RET program aims to do the same while also improving teachers' knowledge about careers in engineering. By emphasizing career information in the learning activities the students participate in, the teachers report that students' knowledge regarding possible engineering careers may increase..$^{20}$ 


\section{Conclusions}

As students progress through school, their passion for learning tends to diminish. ${ }^{21}$ Countless times in the classroom, it has been observed that when students lack interest in the subject, they perform poorly in it. In order to maintain interest, students must associate personal meaning or value in the material they are learning. To facilitate an effective and engaging learning style, learning must be challenging yet interesting. The provision of real-life relevance to the material and the variation of activities, as incorporated in the research-based modules, have been shown to aid in the retention of student motivation. Educators world-wide can benefit from the use of this instrument to gauge student motivation. It would be particularly useful for educators interested in implementing a new format of curriculum: the instrument provides valid evidence that the RET program's research-based Legacy Cycle curriculum has positively affected student learning. In addition, curriculum developers or textbook publishers can utilize this instrument to arrange textbook information in a way that would suit the format of researchbased questions with real-life relevance. Evidently, the student motivation instrument confirms the success of the Vanderbilt University RET Program. The active involvement of K-12 teachers and university faculty in research has brought engineering innovation to classrooms and resulted in lasting relationships between their respective schools and Vanderbilt University. With their experience in the program, RET teachers now have the ability to directly engage their students while increasing student interest and motivation.

\section{Acknowledgments}

The authors wish to thank the National Science Foundation for its support of the RET Sites (EEC-0338092 and EEC-0742871) and VaNTH (EEC-9876363). Any opinions, findings, and conclusions or recommendations expressed in this material are those of the author and do not necessarily reflect the views of the National Science Foundation. The authors also wish to thank former REU students Elizabeth Krebs and Harrison Lamons for their work in designing the instrument.

\section{References}

1. Klein, S.S. Effective STEM Professional Development: A Biomedical Engineering RET Site Project. International Journal of Engineering Education. 25(3):523-533. 2009.

2. Klein-Gardner, S.S. (June 2010). Impact on an RET program on STEM Teachers’ Views of the Nature of Science and the Nature of Science Education. In preparation. 
3. Klein-Gardner, S.S., Johnston, M.E., \& Benson, L. (December 2010). Impact of the RET Teacher-Developed Curriculum on their teaching strategies and student motivation. Submitted to the Journal of Science Teacher Education.

4. English Test. (2010). Retrieved July 1, 2010, from http://www.english-test.net/forum/ftopic14620.html.

5. Klein, S.S. \& Harris, A.H. (2007). A User's Guide to the Legacy Cycle. Journal of Education and Human Development. Vol. 1, Issue 1, p. 1-5.

6. Kurvink, K. (Mar 1993). Contracting as a Motivational Teaching Tool. Journal of College Science Teaching. Vol. 22, No. 5, p. 310.

7. Sahin, M. \& Yorek, N. (July 2009). A Comparison of Problem-based Learning and Traditional Lecture Students' Expectations and Course Grades in an Introductory Physics Classroom. Scientific Research and Essay Vol.4 (8), p. 753-762.

8. Mullamaa, K. (2010). ICT in Language Learning-Benefits and Methodological Implications. International Education Studies, Vol. 3, No. 1.

9. Holmgren, W. (2006). Implementing Biomimicry and Sustainable Design with an Emphasis on the Application of Ecological Principles. Retrieved July 1, 2010 from http://www.teachengineering.org/view_curricularunit.php?url=http://www.teachengineering.org/collection/van_/curr icular_units/van_biomimicry_curricularunit/van_biomimicry_curricularunit.xml.

10. Häussler, P. \& Hoffmann, L. (2002). An Intervention Study to Enhance Girls' Interest, Self-Concept, and Achievement in Physics Classes. Journal of Research in Science Teaching. Vol. 39, No. 9, p. 870-888.

11. Likert, Rensis (1932). "A Technique for the Measurement of Attitudes". Archives of Psychology Vol. 140, p. 155.

12. Cronbach, L. J. (1951). Coefficient alpha and the internal structure of tests. Psychometrika, Vol. 16 No. 3, p. 297-334.

13. Noeth, R. J., Cruce, T., and Harmston, M. T., "Maintaining a Strong Engineering Workforce”, ACT Inc., Iowa City, IA, 2003.

14. Brown, S. C., \& Kysilka, M. L. (2002). Applying Multicultural and Global Concepts in the Classroom and Beyond. Boston: Allyn \& Bacon.

15. Dewey, J. (1938). Logic: The Theory of Inquiry. New York: Holt p. 350.

16. Rhem, J. (1998). Problem Based Learning: An Introduction. The National Teaching \& Learning Forum. Vol. 8 No. 1.

17. Vernon, D.T.A. \& Blake, R.L. (1993). Does Problem-Based Learning Work? A Meta-analysis of Evaluative Research. Acad. Med. 68: 550-563.

18. Conrad, L., Conrad, E., Auerback, J. (2007). The Development, Implementation and Assessment of an Engineering Research Experience for Physics Teachers. American Society for Engineering Education.

19. Kapila, V., (2010). Research Experience for Teachers Site: A Professional Development Project for Teachers. American Society for Engineering Education.

20. Autenrieth, R., Butler-Purry, K., Page, C., Hurtado, L.D., \&Welch, J. (2009). Enrichment Experiences in Engineering (E3) for Teachers Summer Research Program. American Society for Engineering Education. 
21. Lumsden, L.S. (1994). Student Motivation to Learn. Education Resources Information Center Digest, No. 92.

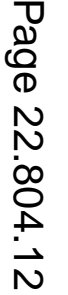

